\title{
Release of \\ Tryptophan and Serotonin into the Portal Vein of the Isolated Perfused Rat Small Intestine*
}

\author{
G. Richter, C.Herrmann, B.Göke*, and R.Arnold \\ Dept. of Internal Medicine, Philipps University of Marburg, Baldinger Strasse, \\ D-3550 Marburg, Federal Republic of Germany
}

\begin{abstract}
Summary. To investigate the release of serotonin from intestinal enterochromaffin cells, we used an in vitro technique which allows studies excluding overlapping influences from outside the gut. The entire small intestine of rats fed a standard or tryptophan-enriched ( $3 \%$ of total) diet was totally isolated by ligatures with the exception of the superior mesentric artery and portal vein that supply and drain the intestine. Simultaneously to the vascular perfusion (Krebs-Ringer bicarbonate buffer, $0,4 \%$ human albumin, $5 \mathrm{~m} M$ glucose, $0.6 \mathrm{~m} M$ glutamine) the gut lumen was infused (buffer or $0.1 \mathrm{~N} \mathrm{HCL}$ ). Acidification of the gut lumen resulted in an increment of venously released tryptophan and serotonin. After feeding tryptophan-enriched food the release of tryptophan was increased. However, the total amount of released serotonin after tryptophan diet did not differ as compared to that after standard diet. Addition of a monoamino-oxidase inhibitor (pargyline) to the arterial perfusate enhanced the released amount of serotonin 3-fold in the portal venous effluent (at a concentration of $1 \mathrm{~m} M$ but not $0.1 \mathrm{~m} M$ ). Recovery studies done by arterial infusions of serotonin $(1 \mu M, 10 \mu M)$ and evaluation of the amounts venously released revealed a high loss of infused serotonin $(40 \%-70 \%)$. Our data suggest gut-born serotonin to more likely play a paracrine role than a role as a classical hormone.
\end{abstract}

Key words: Serotonin - Tryptophan - Small intestine - Rat - Pargyline

\section{Intoduction}

The gastrointestinal tract represents the major source of serotonin in mammals so that circulating serotonin is derived predominanty from mucosal enterochro-

\footnotetext{
* Supported by the Deutsche Forschungsgemeinschaft (grants Go 417/1-1 and Ri 500/1-2) Offprint requests to: Dr. Burkhard Göke, Dep. of Physiology, University of Michigan, Ann Arbor, MI 48109, USA
} 
maffin cells $[2,8,10,13]$. Little is known about the control of serotonin release from such cells or the physiologic functions of serotonin subsequent to its release $[10,22]$. The evidence from previous in vivo studies was largely indirect and circumstantial.

To investigate the release of serotonin from intestinal enterochromaffin cells, we used an in vitro technique which permitted the study of the whole intact small intestine of rats under almost physiologic conditions with access to the gut lumen, arterial and venous circulation. This allowed studies excluding overlapping influences from outside the gut. By use of this approach the release of serotonin and tryptophan after luminal acidification in rats of a standard or tryptophanenriched diet was studies.

\section{Material and Methods}

\section{Animals and Diets}

In one group of female Wistar rats (220-240 g b.wt.) fed a standard diet (Altromin 1324, Lage/Lippe, FRG) the release of tryptophan and serotonin was studied after acidification of the lumen of the isolated perfused small intestine. In a second experimental approach rats (180-220 g b.wt.) were pair-fed a standard or a tryptophan-enriched (L-tryptophan added as $3 \%$ of total diet) food over 10 days. These rats were used for perfusion experiments $(n=15)$ or tissue extractions $(n=12)$. The day before perfusion studies were undertaken the animals were fasted over $12 \mathrm{~h}$ and included into the respective experiments. All rats were anesthetized i.p. with pentobarbitone ( $45 \mathrm{mg} / \mathrm{kg}$ b.wt.).

\section{Perfusion of the Small Intestine}

The preparation of the isolated, perfused small bowel was performed according to Cobb et al. [4]. Oxygenated perfusion fluid entered the gut preparation by way of the aorta through the A. mesenterica superior. A cannula was put into the portal vein and tied for subsequent collection of portal venous effluent. A tube was placed into the proximal duodenum through an incision into the stomach for feeding of the gut lumen. Another tube was inserted into the cecum for the dreinage of feeding fluid. The entire small intestine was vascularly perfused at a constant rate $(4 \mathrm{ml} / \mathrm{min})$ with Krebs-Ringer bicarbonate buffer containing $0.4 \%$ human albumin, $5 \mathrm{~m} M$ glucose, and $0.6 \mathrm{mM}$ glutamine, $37^{\circ} \mathrm{C}$, gassed with $95 \% 0_{2}$ and $5 \% \mathrm{CO}_{2}$. Changes in pressure measured by a Statham pressure transducer connected to a recorder reflected changes in vascular resistance. The gut lumen was fed by way of the tube placed in the duodenum. Feeding rate was $0.38 \mathrm{ml} / \mathrm{min}$. The feeding fluid consisted of Krebs-Ringer bicarbonate buffer or $\mathrm{HCl}(0.1 \mathrm{~N})$ as was suggested previously [23]. One perfusion experiment lasted for $30 \mathrm{~min}$. Over an initial period of $10 \mathrm{~min}$ KRB-buffer was introduced into the gut lumen. Thereafter, acidification of the lumen was performed by $\mathrm{HCl}$ infusion over 10 min followed by $\mathrm{KRB}$ buffer administered over the last $10 \mathrm{~min}$ of perfusion time. The venous effluent of the perfused intestine was collected at 2-min intervals and monitored for tryptophan and serotonin.

\section{Serotonin and Tryptophan Measurements}

In the venously collected samples serotonin and tryptophan concentrations were measured by reverse-phase HPLC using a Waters Radial PAK $\mu$-Bondapak C18 cartridge and a Kontron SFM-23 fluorimeter [24]. The small intestines were extracted as described previously $[21,25]$.

\section{Statistic}

Analysis was performed by the $U$-test of Wilcoxon, Mann and Whitney. 


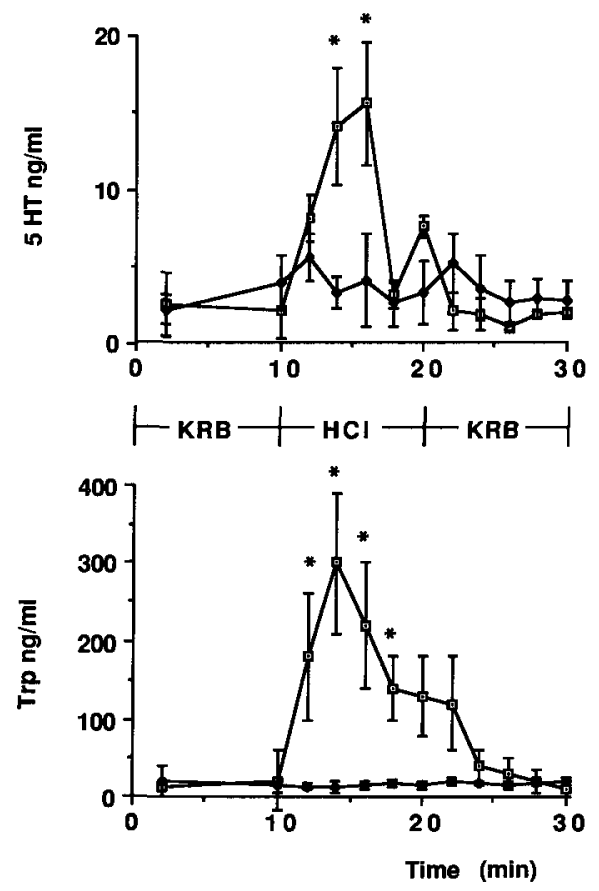

Fig. 1. Release of tryptophan (lower panel) and serotonin (upper panel) from the perfused small intestine after acidification of the gut lumen. Given are means \pm SEM of $n=5$ experiments/group. Asterisks symbolize significance $(p<0.05)$ of the differences between controls (sole KRB-buffer perfusion into the gut lumen; closed circles) or after acidification (open circles)

Table 1.

a Tryptophan and serotonin tissue concentrations in the rat small intestine after administration of a tryptophan-enriched diet

\begin{tabular}{llc}
\hline & $\begin{array}{l}\text { Tryptophan } \\
\text { (ng/g wet weight) }\end{array}$ & $\begin{array}{l}\text { Serotonin } \\
\text { (ng/g wet weight) }\end{array}$ \\
\hline Controls $(n=6)$ & $2100(400)$ & $3291(1343)$ \\
Tryptophan diet $(n=6)$ & $6200(694)^{2}$ & $11430(3033)^{2}$ \\
\hline
\end{tabular}

b Summarized release of tryptophan and serotonin from the perfused intestine; effect of tryptophan-enriched diet and pargyline $(1 \mathrm{~m} M)$

\begin{tabular}{llc}
\hline & $\begin{array}{l}\text { Tryptophan } \\
\text { (ng/30 min) }\end{array}$ & $\begin{array}{l}\text { Serotonin } \\
(\mathrm{ng} / 30 \mathrm{~min})\end{array}$ \\
\hline Standard diet $(n=5)$ & $1152(273)$ & $483(94)$ \\
Tryptophan diet $(n=5)$ & $2634(202)^{2}$ & $583(209$ \\
Tryptophan diet + pargyline $(n=5)$ & $2340(291)^{2}$ & $1399(174)^{2}$ \\
\hline
\end{tabular}

${ }^{2} P \pm 0.05$; given are means (SEM)

\section{Results}

Figure 1 demonstrates the release of tryptophan and serotonin from the perfused intestine after acidification of the gut lumen of rats on standard diet. The release of tryptophan and serotonin was significanctly increased in response to the onset of luminal acid infusion. This effect was reversed again when Krebs-Ringer buffer was infused instead of acid during the last $10 \mathrm{~min}$ of the experiment. Feeding 


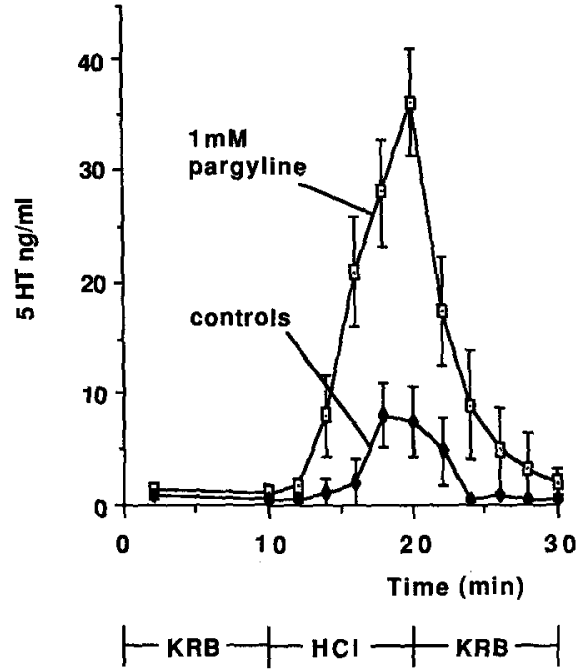

Fig. 2. Effect of $1 \mathrm{~m} M$ pargyline upon serotonin release from the small intestine after tryptophan-rich diet ( $n=5$; open circles). Controls $(n=5$; closed circles) received tryptophan diets, but had no pargyline in the vascularly perfused buffer medium. Given are means $\pm S E M$. For the summarized secretion rates of experiments see Table 1

tryptophan-enriched food increased the tryptophan and serotonin tissue levels (Table 1) in accordance to earlier reported findings [11]. However, the total amounts of released serotonin after tryptophan-enriched food were not significantly different from those released after administration of standard diet. In contrast to this, the released amount of tryptophan after tryptophan-enriched diet was above controls (Table 1).

Addition of the monoamino-oxidase inhibitor pargyline to the perfusate $(1 \mathrm{~m} M)$ enhanced the released serotonin amount from intestines of tryptophanfed rats 3-fold as compared to controls perfused with medium lacking the inhibitor (Fig. 2 and Table 1). Addition of $0.1 \mathrm{~m} M$ pargyline to the perfusate had no effect (data not shown).

Arterial infusion of $1(n=3)$ or $100 \mu M(n=1)$ serotonin drastically increased the vascular resistance measured arterially (mean $\Delta \mathrm{P}$ was $40 \mathrm{mmHG}$ ). These recovery studies performed in single experiments by comparing the venously released amounts of serotonin with those arterially infused revealed a high loss of serotonin ( $40 \%-70 \%$ of infused serotonin) during the vascular passage through the intestinal vascular system. These experiments allowed no precise quantitative analysis, since the observed drastic increase of vascular resistance was accompanied by a development of a significant edema and a progressive loss of vascularly infused buffer volume into the gut lumen.

\section{Discussion}

Previous investigators have predominantly relied on in vivo approaches for studying the release of serotonin from the gut [17]. However, those studies were hampered by methodologic problems in the measurement of circulating concentrations of serotonin $[17,18]$. First, the proper handling of blood samples is a crucial problem since more than $90 \%$ of circulating serotonin is associated with 
platelets and the occurrence of hemolysis alter serotonin measurements grossly. Secondly, when released from intestinal cells most of the serotonin undergoes prompt degradation during its passage through liver and lung [7]. Therefore, serotonin measurements in peripheral blood allow only limited conclusions on the amount of the amine released from gut cells into the portal vein.

The in vitro vascularly perfused small intestine offers advantages as an approach to study the release of serotonin from intestinal cells. The use of buffered, oxygenated salt solutions omits analytical problems otherwise possibly induced by destruction of platelets or hemolysis. The preparation of the isolated rat intestine was demonstrated previously to offer a useful tool in studying the release and catabolism of hormones and other biologic compounds [3, 6, 16, 26, 27]. Perfusions with buffered salt solutions lasting for longer than $30 \mathrm{~min}$ resulted in only a poor viability of the perfused gut tissue $[5,12]$. An improved survival of the in vitro perfused gut was reported before by others using vascularly perfused buffers supplemented with blood cells $[6,15,20]$. However, the need to avoid blood constituents in our experiments is evident. Therefore, we limited our perfusion time to $30 \mathrm{~min}$. Our experiments demonstrated that in accordance with in vivo experiments $[8,23]$ luminal acidification of the gut results in a vascular release of serotonin and tryptophan. The flow rate in the portal vein remained constantly during acidification. This was controlled by an evaluation of the venously released volumes of effluents per time interval which remained unaltered. Furthermore, the vascular resistance measured arterially increased only slightly. Therefore, a change of flow rates as consequence of luminal acidification which could possibly influence the serotonin concentrations measured in the effluents was not observed. We have not studied the morphological appearance of the gut mucosa after perfusion with hydrochloric acid. This was done earlier by Resnick and Gray [23]. They reported a reduction of the serotonin content of the upper small intestine of rats and a degranulation of argentaffin cells by perfusion of the gut lumen with $0.1 \mathrm{~N}$ hydrochloric acid. In these experiments histological studies of the small intestine revealed no gross morphological abnormality after intraluminal $\mathrm{HCl}$. Released from gut cells rapid degradation of the biogenic amines occurs. This can be ascribed to amine uptake mechanisms [7] and inactivating enzymatic activities [7] in the gut. The resulting serotonin inactivating effect has a big capacity, since even administration of tryptophan-enriched food did not enhance the vascularly released serotonin amount, and an arterial infusion of serotonin resulted in high losses of the amine when recovery measurements were performed in the venous effluents. Our data obtained by use of a MAOinhibitor (pargyline) support the concept of a major role for monoamino-oxidase activities in the degradation of vascular released serotonin in rats.

In summary, the present data make a role for intestinal serotonin as a "classical" circulating hormone rather unlikely. However, it is possible that the well known uptake of serotonin into platelets [7] leads to physiological relevant survival of intestinal serotonin in the circulation. Otherwise, a paracrine or "local" role for the amine, e.g. in the regulation of local blood flow, could be of importance. Recent evidence for a physiologic role of intraluminally released serotonin emphasize the possible importance of serotonin as local modulator of intestinal functions $[9,14,19]$. 
Acknowledgements. The results are part of the doctoral thesis of Ms. C. Herrmann. It was presented at the 88th Annual Meeting of the American Gastroenterological Association, May 9-15, 1987, Chicago, Ill., USA, and has appreared in abstract form in 1987 (Gastroenterology $92: 1407)$.

\section{References}

1. Ahlmann H, Bhargava HN, Dahlström A, Larsson I, Newson B, Pettersen G (1981) On the presence of serotonin in the gut lumen and possible release mechanism. Acta Physiol Scand 112:262-269

2. Ahlmann H, Dahlström A (1982) Storage and release of 5-hydroxytryptamine in enterochromaffin cells of the small intestine. In: de Clerck F, Vanhoutte PM (eds). 5-Hydroxytryptamine in peripheral reactions. Raven Press, New York, pp 1-21

3. Burks TF, Long JP (1966) Catecholamine-induced release of 5-hydroxytryptamine (5-HT) from perfused vasculature of isolated dog intestine. J Pharm Sci 55:1383-1386

4. Cobb CF, Van Thiel DH, Wargo J (1983) Ethanol inhibition of glucose absorption in isolated, perfused small bowel in rats. Surgery $94: 199-203$

5. Cohen BE, Folkman MJ (1968) Cell death and the measurement of oxygen consumption in the isolated perfused organ. In: Norman $\mathbf{J}(\mathrm{ed})$ Organ perfusion and preservation. Appleton-Century-Crofts, New York, pp 863-875

6. Cuber JC, Vilas F, Charles N, Sahraoui M, Bernard C, Chayvialle JA (1988) Bombesin and nutrients stimulate the release of intestinal cholecystokinin through distinct pathways in rats. Gastroenterology $94: \mathrm{A} 81$

7. Douglas WW (1980) Histamine and 5-hydroxytryptamine (serotonin) and their antagonists. In: Gilman AG, Goodman LS, Gilman A (eds) The pharmacological basis of therapeutics, 6th ed. Macmillan, New York Toronto London, pp 609-646

8. Erspamer V (1966) Occurrence of indoalkyl amines in nature. In: Eichler O, Farah A (eds) Handb exp pharmacol, vol 19. Springer, Berlin Heidelberg New York, pp 132-181

9. Ferrara A, Zinner MJ, Jaffe BM (1987) Intraluminal release of serotonin, substance P, and gastrin in the canine small intestine. Dig Dis Sci 32:289-294

10. Forsberg EJ, Miller RJ (1983) Regulation of serotonin release from rabbit intestinal enterochromaffin cells. J Pharmacol Exp Ther 227:755-766

11. Göke B, Richter G, Grebe A, Keim V, Arnold R (1987) Tryptophan-rich diet as a new approach to study the serotoninergic enteropancreatic axis. Gut 28 S1:203-205

12. Göke B, Schwartz P, Ralph G, Creutzfeldt W (1984) Zur Morphologie des isoliert perfundierten Rattendünndarmes. Verh Dtsch Ges Inn Med 90:1606-1609

13. Grahame-Smith DG (1988) Serotonin (5-hydroxytryptamine, 5-HT). Q J Med, New Series $67,254: 459-466$

14. Gronstadt K, Dahlström A, Florence L, Zinner MJ, Ahlmann J, Jaffe BM (1987) Regulatory mechanisms in endoluminal release of serotonin and substance $P$ from feline jejunum. Dig Dis Sci 32:393-400

15. Hohenleitner FJ, Senior JR (1969) Metabolism of canine small intestine vascularly perfused in vitro. J Appl Physiol 26:119-128

16. Hsueh W, Gonzalez-Crussi F, Arroyave JL (1986) Release of leukotriene C4 by isolated, perfused rat small intestine in response to platelet-acitivating factor. J Clin Invest 78:108114

17. Jaffe BM, Kellum JM, Kopen DF, Stechenberg L (1978) Release and physiologic action of serotonin. In: Bloom SR (ed) Gut hormones. Churchill Livingstone, Edingburgh London New York, pp 515-523

18. Kellum JM, Jaffe BM (1976) Release of immunoreactive serotonin following acid perfusion of the duodenum. Ann Surg 184:633-636

19. Mätensson HG, Zinner MJ, Jaffe BM (1986) Effects of intraluminal perfussion with serotonin on jejunal motility. Dig Dis Sci 31:811-816

20. Nicholls TJ, Leese HJ, Bronk JR (1983) Transport and metabolism of glucose by rat small intestine. Biochem J 212:183-187 
21. Noll B, Göke B, Willemer S, Richter G, Arnold R (1988) Influence of experimental hyperthyroidism on blood and myocardial serotonin in rats. Res Exp Med 188:433-442

22. Pettersen G, Dahlström A, Larsson I, Lundberg JM, Ahlmann H, Kewenter J (1978) The release of serotonin from rat duodenal enterochromaffin cells by adrenoreceptor agonist studied in vitro. Acta Physiol Scand 103:219-224

23. Resnick RH, Gray SJ (1962) Chemical and histological demonstration of hydrochloric acic-induced release of serotonin from intestinal mucosa. Gastroenterology 42:48-55

24. Richter G, Stöckmann F, Conlon JM, Creutzfeldt W (1986) Serotonin release into blood after food and pentagastrin. Studies in healthy subjects and in patients with metastatic carcinoid tumors. Gastroenterology $91: 612-618$

25. Richter G, Ballmann M, Conlon JM (1986) Effect of streptozotocin administration upon serotonin content of the pancreas and the small intestine of the rat. Horm Metab Res 18: 663-665

26. Schwörer H, Racke K, Kilbinger H (1987a) Temperature-dependent effects on increased intraluminal pressure on serotonin release from the vascularly perfused guinea pig ileum. Naunyn-Schmiedebergs Arch Pharmacol 336:483-486

27. Schwörer H, Racke K, Kilbinger H (1987b) Spontaneous release of endogenous 5-hydroxytryptamine and 5-hydroxyindolacetic acid from the isolated vascularly perfused ileum of the guinea pig. Neuroscience $21: 297-303$

Received December 28, 1988/ Accepted April 10, 1989 